\title{
BEARING CAPACITY AND ENERGY ABSORPTION CHARACTERISTICS OF THIN-WALLED CIRCULAR STEEL TUBE AND ITS APPLICATION IN RETRACTABLE ROOF STRUCTURES
}

\author{
Qinghua $\operatorname{Han}^{1,2, *}$, Yan Lu ${ }^{1}$, Zemin Xu ${ }^{1}$ and Yafei Chang ${ }^{1}$ \\ ${ }^{1}$ School of Civil Engineering, Tianjin University, Tianjin 300072, China \\ ${ }^{2}$ Key Laboratory of Coast Structure Safety (Tianjin University), \\ Ministry of Education, Tianjin 300072, China \\ *(Corresponding author: E-mail: qhhan@tju.edu.cn)
}

Received: 2 August 2010; Revised: 10 November 2010; Accepted: 25 February 2011

\begin{abstract}
This paper presents an experimental task in which the specimens are either single thin-walled circular stainless steel tubes or a honeycomb structure. The honeycomb structure is made up of the tubes with 4 configurations. Compressive loads are applied and deformations are recorded. The numerical and analytical analyses are also carried out with respect to the bearing capacity and energy absorption characteristics. It is shown that the average bearing capacity of single thin-walled circular steel tubes is lower than those tubes arranged in a honeycomb structure. The configuration of staggered thin-walled circular steel tubes with $R / t$ values between 20 and 30 exhibits good bearing capacity. The configuration of aligned thin-walled circular steel tubes of $R / t$ values between 30 and 45 exhibits good energy absorbing characteristic. The results obtained in this paper may be useful in designing a steel retractable roof structure with respect to passive collision protection.
\end{abstract}

Keywords: Thin-walled circular steel tube, Honeycomb structure, Bearing capacity, Energy absorption, Aligned configuration, Staggered configuration

\section{INTRODUCTION}

Many researches on the thin-walled circular tube under different loads were conducted. Abrahamson [1] firstly studied the dynamic plastic flow buckling of a cylindrical shell from uniform radial impulse procedures. And the radical impact experiment of the single cylindrical shell was carried out. The buckling wave shape was observed. His finding is buckling modal number and critical impact velocity which fit the experimental results. Lindberg [2] made further research on the dynamic plastic flow buckling of a cylindrical shell from uniform radial impulse procedures considering the strain rate influence. The buckling modal number of the cylindrical shell was further studied. Selecting aluminum spherical shells of $R / t$ values between 15 and 240 axially compressed, Gupta et al. [3-4] drew the load-compression and energy-compression curves and determined the mean collapse loads. They found a simple analytical model which matched well with the experimental results. $\mathrm{Ru}$ and Wang et al. exploration on the plastic buckling of a cylindrical shell under radial impulse load by the energy principle acquired the equation of the critical impact velocity [5]. Gu and Liu [6] presented the assumed energy of the displacement field to study the dynamic plastic buckling of a cylindrical shell fixed at both ends under impulse load. Their conclusion is that fixed boundary condition makes plastic buckling stronger than the free boundary condition. Zeng et al. [7] conducted a series of experiment on thin-wall circular steel tube under shock wave. They acquired the modal solution based on the principle of the virtual velocity. It reports that the deformation of steel tubes are controlled by changing the material hardening, layer and inertia. Gu [8] and Du et al. [9] also conducted the experimental research and theoretical analysis about the deformation and energy absorption characteristics of multi-row cylindrical shell under explosion and shock waves, which serves as the analytical method for this paper. 
At present, thin-walled circular tubes have many applications. Thin-walled circular tubes may be applied in long-span space structure design. Retractable roof structure is an advanced long-span space structure. Compared with the traditional structures, retractable roof structure is a moving system, which can be used in partially or entirely open or closed conditions. The research on the retractable roof structure is only about design principle, load, load combination and so on. Zhang and Liu [10] firstly summarized the developing trend of retractable roof structure and put forward the retractable principle and methods based on the architecture plane projection and elevation. Then Guan et al. [11] presented wire-driven track system and explained the differences of the load value and load combination between the retractable roof structure and traditional structure. Ishii [12] introduced the basic concept of retractable roof structure and building function. Then the typical construction examples are introduced. When retractable roof structure is moving, it may cause collision accidents. There is few research on the collision mechanism and passive safety protection. Passive safety protection [13] aims at reducing the damage after the collision accidents of movable elements, avoiding the casualties. And the relevant technique contains crashworthy design, personal evacuation and rescue.

The application of thin-walled circular steel tube in designing a steel retractable roof structure is discussed with respect to passive collision protection. In this paper, thin-walled circular stainless steel tube of $D$ values between $19 \mathrm{~mm}$ and $51 \mathrm{~mm}$ and $t$ values between $0.3 \mathrm{~mm}$ and $1.4 \mathrm{~mm}$ are selected for the research. The main mechanical parameters are shown in Table 1. An experimental task was presented in which the specimens are either single thin-walled circular stainless steel tubes or a honeycomb structure. The honeycomb structure is made up of the tubes with 4 configurations. Compressive loads were applied and deformations are recorded. The numerical and analytical analyses are also carried out with respect to the bearing capacity and energy absorption characteristics. The given numerical simulation aims at verifying the experimental results.

Table 1. Mechanical Properties of the Thin-walled Circular Steel Tube

\begin{tabular}{|c|c|c|c|}
\hline Material & Elastic Modulus (GPa) & Yield Stress ( MPa ) & Density ( kg/m ${ }^{3}$ ) \\
\hline Stainless Steel & 190 & 347 & 7850 \\
\hline
\end{tabular}

\section{ANALYSIS OF THE THIN-WALLED CIRCULAR TUBE UNDER STATIC COMPRESSION}

\subsection{Ultimate Internal Forces of Single Circular Tube under Two-way Symmetrical Compression}

Two-way symmetrical compression is the basic form for thin-walled circular tube. The corresponding simplified model is shown in Figure 1(a). [8]

Under static load, single tube under two-way symmetrical compression is a hyperstatic structure with three redundances. Based on the symmetry, a quarter of the structure is extracted, which is a hyperstatic structure with one redundance (Figure 1 (b)). The basic structure is a curved beam. In polar coordinate system, by the method of forces the final moment is shown as

$M(\alpha)=F R\left(\frac{1}{\pi}-\frac{\sin \alpha}{2}\right)$

When $\quad \alpha=\frac{\pi}{2}, \quad M\left(\frac{\pi}{2}\right)=\left(\frac{1}{\pi}-\frac{1}{2}\right) F R=-0.182 F R$ 
When $\alpha=0, M(0)=\frac{F R}{\pi}=0.318 F R$.

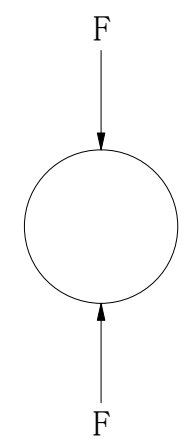

(a) Simplified Model

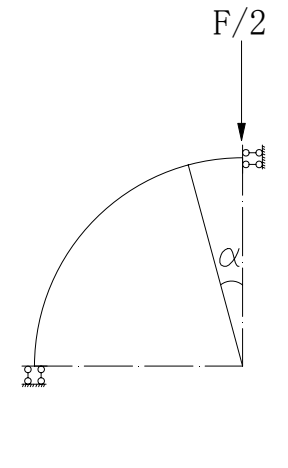

(b) Hyperstatic Structure with One Redundance

Figure 1. Internal Forces of Single Circular Tube under Two-way Symmetrical Compression

In the compression course, there are four plastic hinges where $\alpha=0, \alpha=\frac{\pi}{2}$ and the symmetrical points. The first plastic hinge appears at the point of $\alpha=0$, which makes the tube deforming as the shape of dumbbell. This mechanical behavior leads to the failure form of four plastic hinges.

According to the formula for calculating the maximum bending stress

$\sigma_{\max }=\frac{M_{\max }}{W}$

For the rectangular section,

$W=\frac{L t^{2}}{6}$

Putting Eq. 3 and Eq. 5 into Eq. 4 ,

$F=\frac{L \sigma_{\max }}{0.546} \cdot \frac{t^{2}}{D}$

When $\sigma_{\max }=f$, the yield load of single tube under two-way symmetrical compression is shown in Eq. 7

$F_{f}=\frac{L f}{0.546} \cdot \frac{t^{2}}{D}$

Eq. 7 shows that the yield load of single circular tube under two-way symmetrical compression is related to $\frac{D}{t}$. 


\subsection{Ultimate Internal Forces of Honeycomb Circular Tubes under Compression}

Thin-walled circular tubes are arranged as a honeycomb structure. The general configurations are aligned configuration and staggered configuration (Figure 2) [8].

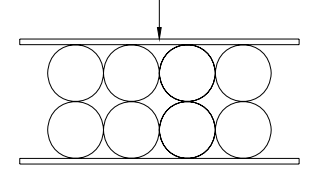

(a) Aligned Configuration

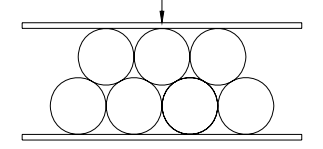

(b) Staggered Configuration

Figure 2. Honeycomb Structure

\subsubsection{Ultimate Internal Forces of Aligned Circular Tubes under Compression}

When the configuration is aligned configuration, the mechanical mode of one tube is shown in Figure 3 (a). Based on the symmetry, a quarter of the structure is extracted, which is a hyperstatic structure with two redundances (Figure 3 (b)). The basic structure is also a curved beam [8].

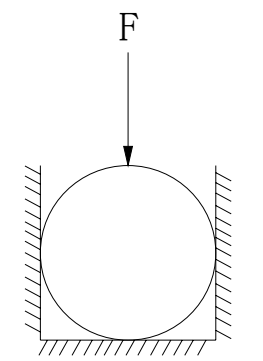

(a)Simplified Model

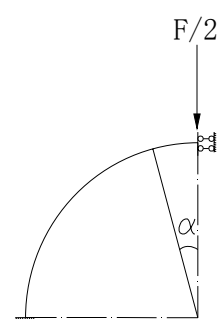

(b)Hyperstatic Structure with Two Redundances

Figure 3. Internal Forces of Aligned Circular Tubes under Compression

By the method of forces, calculate the section moment of the curved beam. And the maximum of section moment can be acquired when $\alpha=0$.

$M_{\max }=0.15 F R$

Putting Eq. 5 and Eq. 8 into Eq. 4, the yield load of aligned circular tubes under compression is derived when $\sigma_{\max }=f$.

$F_{f}=\frac{L f}{0.9} \cdot \frac{t^{2}}{D}$

\subsubsection{Ultimate Internal Forces of Staggered Circular Tubes under Compression}

When the configuration is staggered configuration, the mechanical mode of one tube is shown in Figure 4 (a). Based on the symmetry, a third of the structure is extracted, which is a hyperstatic structure with two redundances (Figure 4 (b)). The basic structure is also a curved beam [8]. 


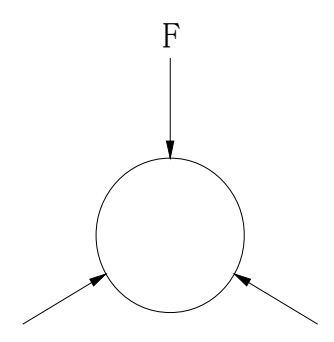

(a)Simplified Model

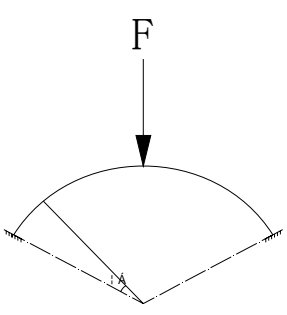

(b) Hyperstatic Structure with Two Redundances

Figure 4. Internal Forces of Staggered Tubes under Compression

Based on Figure 4, the maximum moment of staggered circular tubes under compression is as follows when $\alpha=\frac{\pi}{3}$.

$M_{\max }=0.19 F R$

The yield load of staggered circular tubes under compression is shown as

$F_{f}=\frac{L f}{0.88} \cdot \frac{t^{2}}{D}$

\section{STATIC COMPRESSION EXPERIMENT OF THIN-WALLED CIRCULAR STEEL TUBES}

\subsection{Experimental Research}

Static compression experiments were conducted using the thin-walled circular steel tubes with 25 sizes and 4 configurations. The bearing capacity and energy absorption characteristics for thin-walled circular steel tubes under static compression were studied. The whole absorbed energy was acquired by the internal of load-displacement curve. Because the mass of the circular steel tube affects the energy absorption characteristics. Specific energy absorption was calculated. After the experiment, bearing capacity and energy absorption characteristics of the circular steel tubes were carefully analyzed so as to obtain the optimal configuration and the size of the tubes.

The experimental material was thin-walled circular stainless steel tube with 5 different diameters and 5 different thicknesses respectively. And $L=200 \mathrm{~mm}$. The main mechanical parameters were shown in Table 1 . The load speed was $15 \mathrm{~mm} / \mathrm{min}$. When the circular steel tube was flattened, load-displacement curve was recorded. The circular steel tube of each size was compressed three times. The average value was used as final experimental result.

Because the tube size of $25 \mathrm{x} 0.7$ is usually used in the project, this circular steel tubes consist of the honeycomb structure. The circular steel tubes with 4 configurations were compressed, and the load-displacement curves were acquired. The configurations are shown in Figure 5. 


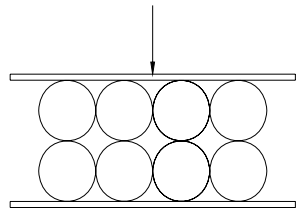

(a) Aligned Configuration with Two Row

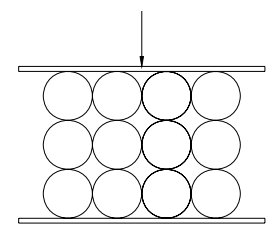

(c) Aligned Configuration with Three Row

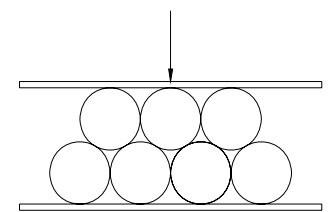

(b) Staggered Configuration with Two Row

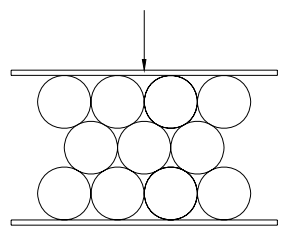

(d) Staggered Configuration with Three Row

Figure 5. Configuration of Honeycomb Thin-walled Circular Steel Tubes

\subsection{Experimental Results and Analysis}

\subsubsection{Static Compression Experiment of Single Circular Steel Tube}

The states of deformation of single circular steel tube are shown in Figure 6. According to the experimental results, different sizes of single circular tubes obtained similar load-displacement curves. At the beginning, the load-displacement curve is linear, and the time duration is short. As the load increases, the single circular steel tube begins to yield, and the yield point elongation is present. At this time, the displacement increases gently. This phrase is the major energy-consuming stage. In the course of compression, there are two sharp points, which are plastic hinges. The contact zone between compression surface and the circular steel tube and that between the bearing surface and the circular steel tube gradually expands. At the end, the load increases sharply, and the circular steel tube has the shape of dumbbell. Finally the contact zone completely expands, and the process of energy absorbing is completed.

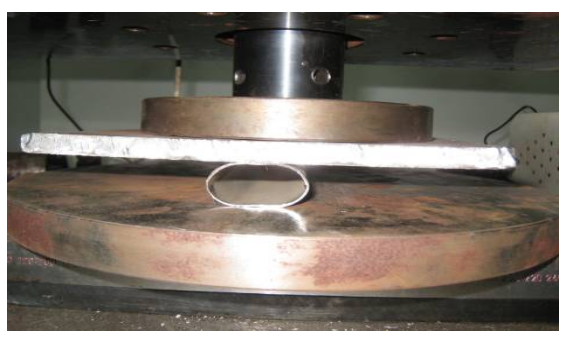

(a) Initial Stage

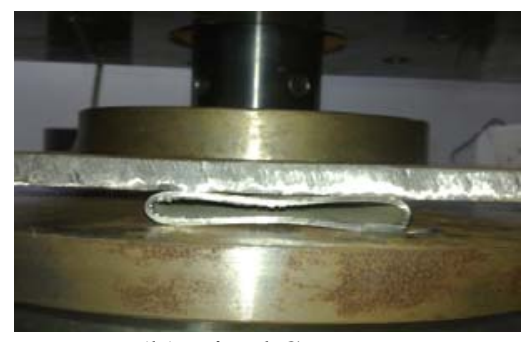

(b) Final Stage

Figure 6. Static Compression Experiment of Single Circular Steel Tube

The load-displacement curve for 5 kinds of thin-walled circular steel tubes with the same thickness and different outer diameter selected for the experiments can be seen in Figure 7. When tube thickness keeps the same, the yield load decreases and the elongation in the yield point increases with the increment of the outer diameter. At the same time, five groups' thin-walled circular steel tubes with the same outer diameter and different thickness are selected for thickness effect (Figure 8). From the load-displacement curves, with the increment of the tube thickness, the yield load of single circular steel tube increases, but the length of the yield point elongation is the same. The total absorbing energy also increases. 


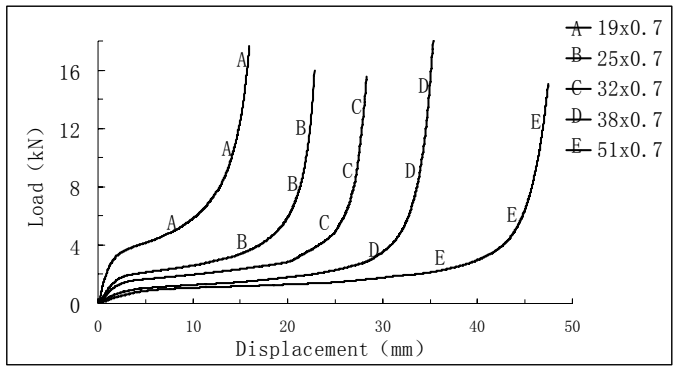

Figure 7. Load-Displacement Curve (Same Thickness)

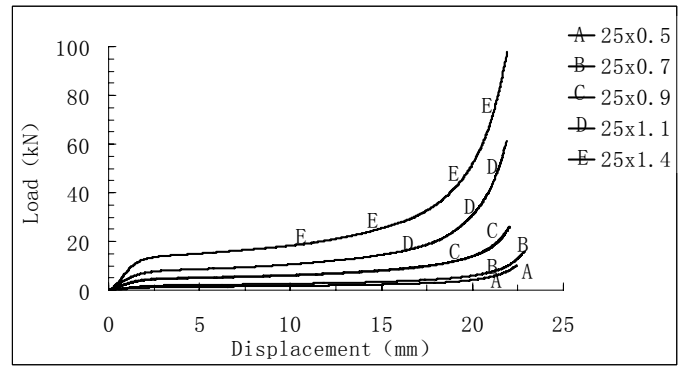

Figure 8. Load-Displacement Curve (Same Outer Diameter)

By internal calculating of the load-displacement curves, the absorbing energy curves of single circular steel tube can be seen in Figure 9. Specific energy absorption (SEA) is the absorbed energy of the unit-mass in the whole compression. From the curves, as the thickness of the circular steel tube with the same outer diameter increases, SEA increases and the increment trend of SEA tends to be slow. With the increment of the outer diameter, SEA of the tube with the same thickness decreases.

When the length of the circular steel tube is a fixed value, SEA relates to $D / t$. From Figure 10, the relation between the absorbing energy of single circular steel tube and $D / t$ is approximately modeled as a power exponent function when $L$ is a fixed value. As the value of $D / t$ increases, SEA decreases. When the value of $D / t$ ranges from 30 to 45, the absorbing energy of single circular steel tube is large, but the impact force is small. When the value of $D / t$ ranges from 20 to 30 , the impact force of single circular steel tube is large, but the absorbing energy is small.

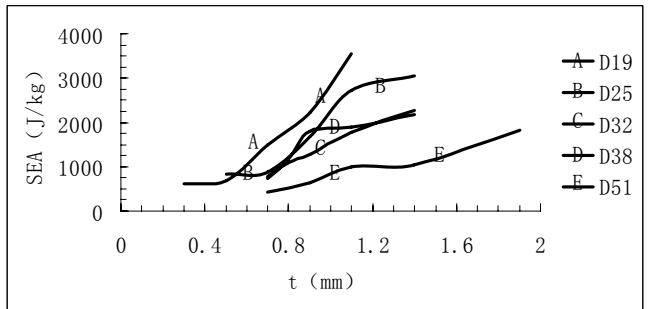

Figure 9. Curve of SEA with the Change of $D$ and $t$

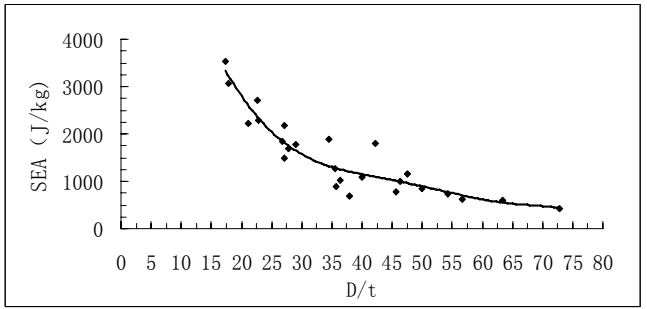

Figure 10. Curve of SEA and $D / t$

\subsubsection{Static Compression Experiment of Honeycomb Thin-walled Circular Steel Tubes}

According to the configuration shown in Figure 4, the tubes with the size of $25 \mathrm{x} 0.7$ were selected for the experiment. The load-displacement curve were written down. One tube's bearing capacity of honeycomb thin-walled circular steel tubes is similarly equal to the whole bearing capacity divided by the number of the bottom tubes [8]. The compression course is shown in Figure 11, taking the two-row and aligned configuration for example. 


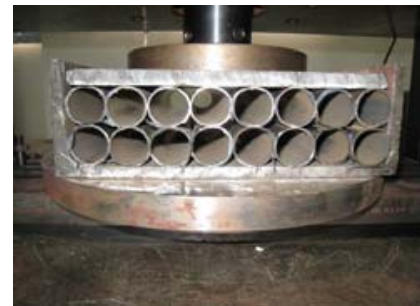

(a) Stage 1

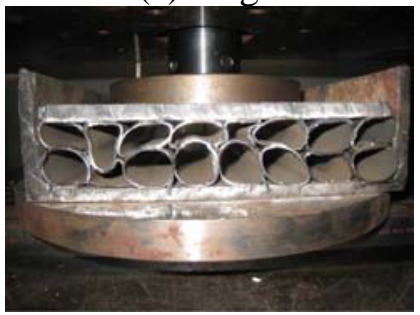

(d) Stage 4

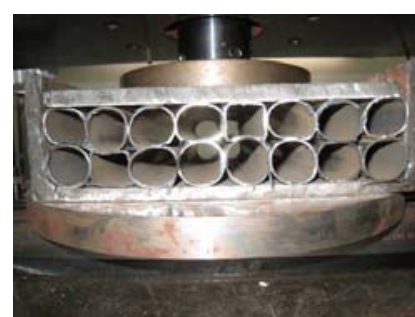

(b) Stage 2

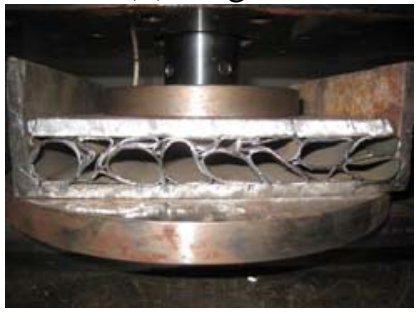

(e) Stage 5

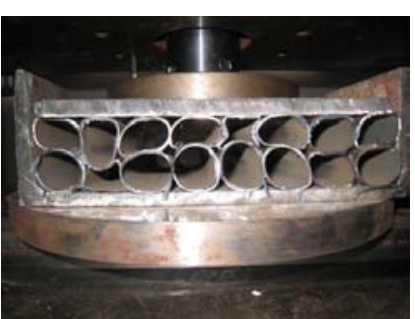

(c) Stage 3

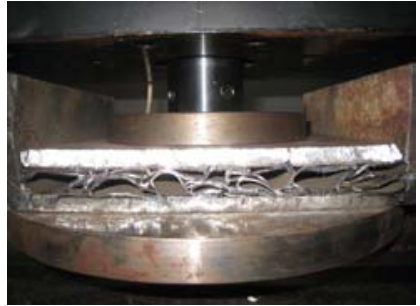

(f) Stage 6

Figure 11. Compression Course of Honeycomb Thin-walled Circular Steel Tubes (Two-row and Aligned Configuration)

According to Figure 11, the circular steel tube yields by row. Considering the influence of the material nonuniformity and experiment condition, the yield tubes are not in the same row, but the number of the yield tubes is similarly equal to that of the tubes in the same row.

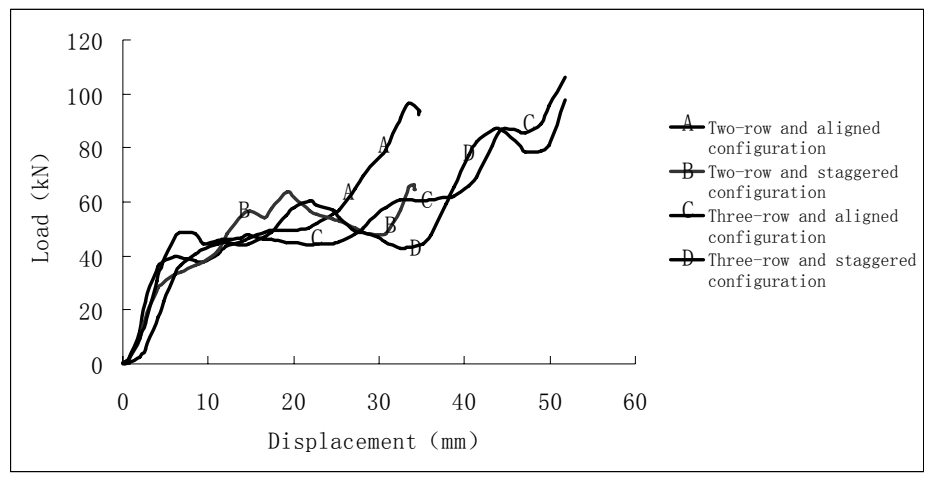

Figure 12. Load-displacement Curve of Honeycomb Thin-walled Circular Steel Tubes

Load-displacement curves of honeycomb thin-walled circular steel tubes are shown in Figure 12. And the trend of four curves is similar. At the beginning, elastic deformation occurs and the load-displacement curve is linear. When the load increases, some circular tubes begin to yield and deformation increasingly extends. As the load continues to increase, inflexion in the curve occurs and the curve increases zigzagly. The reason is that there are large gaps among the tubes and less constraint of the tubes. The deformation increases into the gaps. Finally the circular tubes are flattened. The process of energy absorbing is completed. 


\section{NUMERICAL SIMULATION OF STATIC COMPRESSION OF THIN-WALLED CIRCULAR STEEL TUBES AND RESULTS COMPARSION}

\subsection{Numerical Simulation of Static Compression of Single Circular Steel Tube and Results Comparison}

The numerical simulation of the circular steel tube is made by the software ANSYS /LS-DYNA[14]. The model size is the same as the size in the experiment. The material of the steel plates is low-carbon steel. Its size is 240x100x10. Mechanical properties are shown in Table 2.

Table 2. Mechanical Properties

\begin{tabular}{|c|c|c|c|c|c|c|c|}
\hline Material & $\begin{array}{c}\text { Elastic } \\
\text { Modulus } \\
(\mathrm{GPa})\end{array}$ & $\begin{array}{c}\text { Yield } \\
\text { Stress } \\
(\mathrm{MPa})\end{array}$ & $\begin{array}{c}\text { Tangent } \\
\text { Modulus } \\
(\mathrm{GPa})\end{array}$ & $\begin{array}{c}\text { Poisson } \\
\text { Ratio }\end{array}$ & $\begin{array}{c}\text { Density } \\
\left(\mathrm{kg} / \mathrm{m}^{3}\right)\end{array}$ & $\begin{array}{c}\text { Static } \\
\text { Friction } \\
\text { Coefficient }\end{array}$ & $\begin{array}{c}\text { Dynamic } \\
\text { Friction } \\
\text { Coefficient }\end{array}$ \\
\hline Stainless Steel & 190 & 347 & 10 & 0.3 & 7850 & 0.15 & 0.1 \\
\hline $\begin{array}{c}\text { Low-carbon } \\
\text { steel }\end{array}$ & 210 & $/$ & $/$ & 0.3 & 7850 & $/$ & $/$ \\
\hline
\end{tabular}

In the numerical simulation, bilinear isotropic hardening material model is adopted for the circular stainless steel tube. The circular steel tube is simulated with SHELL163. The steel plate is simulated with SOLID164 and a rigid model. The contact between steel plate and circular steel tube is modeled as the automatic surface to surface contact. The contact between circular steel tubes is automatic single surface contact. The contact method is penalty method. This method is commonly used in analyzing the contact of shell element. In the contact analysis, the thickness change of the shell element is considered. The model is shown in Figure 13.

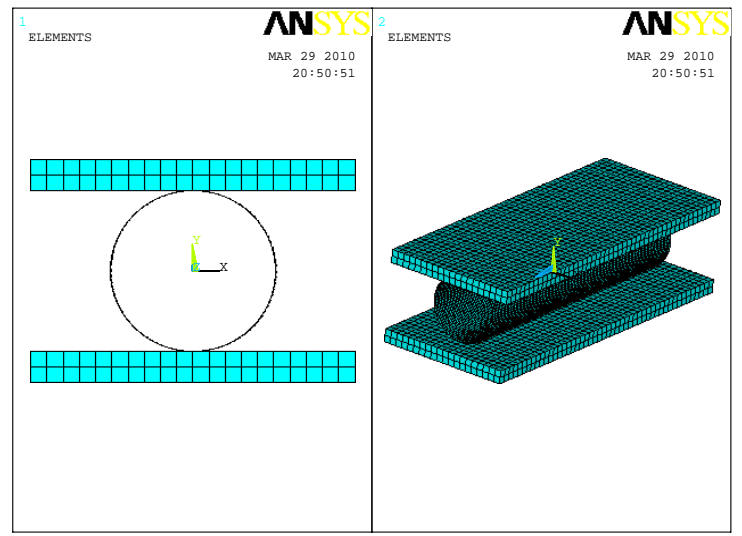

Figure 13. Numerical Analysis Model of Single Circular Steel Tube

The load-displacement curve and absorbed energy of single circular steel tube is shown in Figure 14, taking the circular tube with the size of $200 \times 25 \times 0.7$ for example. The compression course can be divided into 3 phases: elastic phase, plastic phase, compaction and strength phase. At first, elastic deformation occurs. When the displacement is about $5 \mathrm{~mm}$, plastic yield phase begins and plastic level occurs. It is the main phase for absorbing energy. When the displacement is about $15 \mathrm{~mm}$, it is compaction and strength phase and the load sharply increases. After this phase, the tube can not absorb energy. In the numerical analysis, the yield load is $2.33 \mathrm{kN}$ comparing with $2.51 \mathrm{kN}$ in theory. The absorbed energy in the whole compression in numerical analysis can be directly acquired from the analysis result. The result in numerical analysis tallies with the experiment result. When the displacement comes to about $15 \mathrm{~mm}$, the stain energy is $82.65 \mathrm{~J}$ compared with $73.8 \mathrm{~J}$ in the experiment. When the displacement does not exceed the half of the outer diameter, the absorbing energy increases linearly. 


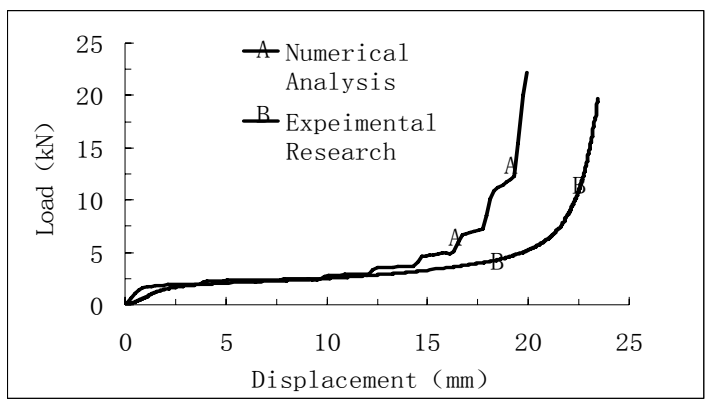

Figure 14. Load-displacement Curve of Static Compression of Single Circular Steel Tube

After theoretical analysis, experiment research and numerical simulation, results comparison about the yield load, the whole absorbing energy and SEA are listed (Table 3). Results of theoretical analysis, experiment research and numerical simulation agree well. It proves that it is suitable and reliable for the numerical simulation.

Table 3. Results Comparison of Theoretical Analysis, Experiment Research and Numerical Simulation

\begin{tabular}{|c|c|c|c|c|c|c|c|c|}
\hline $\begin{array}{l}\text { Size of } \\
\text { the Tube } \\
\text { ( LxDxt) }\end{array}$ & $\begin{array}{c}\text { Mass } \\
(\mathrm{kg})\end{array}$ & $\begin{array}{l}\text { Yield } \\
\text { Load } \\
(\mathrm{An} .) \\
(\mathrm{kN}) \\
\end{array}$ & $\begin{array}{l}\text { Yield } \\
\text { Load } \\
(\text { Ex. }) \\
(\mathrm{kN}) \\
\end{array}$ & $\begin{array}{l}\text { Yield } \\
\text { Load } \\
(\mathrm{Nu} .) \\
(\mathrm{kN}) \\
\end{array}$ & $\begin{array}{c}\text { Whole } \\
\text { Absorbing } \\
\text { Energy } \\
(\text { Ex. })(\mathrm{J})\end{array}$ & $\begin{array}{l}\text { SEA } \\
(\text { Ex. }) \\
(\mathrm{J} / \mathrm{kg})\end{array}$ & $\begin{array}{c}\text { Whole } \\
\text { Absorbing } \\
\text { Energy } \\
(\text { Ex. })(\mathrm{J})\end{array}$ & $\begin{array}{l}\text { SEA } \\
(\text { Ex. }) \\
(\mathrm{J} / \mathrm{kg})\end{array}$ \\
\hline $200 \times 19 \times 0.3$ & 0.03 & 0.61 & 0.61 & 0.74 & 16.85 & 609.05 & 18.01 & 650.92 \\
\hline $200 \times 19 \times 0.5$ & 0.05 & 1.69 & 1.43 & 1.78 & 31.06 & 680.79 & 37.22 & 815.85 \\
\hline $200 \times 19 \times 0.7$ & 0.06 & 3.31 & 4.00 & 4.06 & 94.58 & 1497.07 & 107.00 & 1693.60 \\
\hline $200 \times 19 \times 0.9$ & 0.08 & 5.47 & 6.43 & 7.19 & 178.67 & 2223.85 & 185.00 & 2302.65 \\
\hline $200 \times 19 \times 1.1$ & 0.10 & 8.16 & 10.16 & 11.03 & 343.96 & 3541.92 & 349.00 & 3593.82 \\
\hline $200 \times 25 \times 0.5$ & 0.06 & 1.28 & 1.26 & 1.38 & 50.35 & 833.43 & 58.10 & 961.65 \\
\hline $200 \times 25 \times 0.7$ & 0.08 & 2.51 & 2.20 & 2.85 & 73.84 & 880.11 & 74.90 & 892.80 \\
\hline $200 \times 25 \times 0.9$ & 0.11 & 4.15 & 4.89 & 6.08 & 180.46 & 1686.94 & 121.01 & 1131.20 \\
\hline $200 \times 25 \times 1.1$ & 0.13 & 6.21 & 8.20 & 8.09 & 351.96 & 2714.42 & 316.01 & 2437.18 \\
\hline $200 \times 25 \times 1.4$ & 0.16 & 10.05 & 11.33 & 13.10 & 498.67 & 3060.22 & 468.02 & 2872.11 \\
\hline $200 \times 32 \times 0.7$ & 0.11 & 1.96 & 2.02 & 1.98 & 83.77 & 775.19 & 89.80 & 831.02 \\
\hline $200 \times 32 \times 0.8$ & 0.12 & 2.56 & 2.47 & 3.13 & 134.72 & 1094.39 & 154.21 & 1252.69 \\
\hline $200 \times 32 \times 0.9$ & 0.14 & 3.25 & 3.76 & 4.02 & 175.68 & 1272.63 & 186.25 & 1349.18 \\
\hline $200 \times 32 \times 1.1$ & 0.17 & 4.85 & 6.06 & 6.01 & 296.59 & 1769.24 & 294.01 & 1753.83 \\
\hline $200 \times 32 \times 1.4$ & 0.21 & 7.85 & 9.35 & 9.81 & 481.44 & 2278.62 & 462.31 & 2188.07 \\
\hline $200 \times 38 \times 0.7$ & 0.13 & 1.65 & 1.50 & 1.53 & 93.30 & 724.52 & 104.12 & 808.55 \\
\hline $200 \times 38 \times 0.8$ & 0.15 & 2.16 & 2.45 & 2.98 & 168.54 & 1148.28 & 179.03 & 1219.75 \\
\hline $200 \times 38 \times 0.9$ & 0.16 & 2.73 & 4.09 & 3.51 & 296.71 & 1801.77 & 265.35 & 1611.31 \\
\hline $200 \times 38 \times 1.1$ & 0.20 & 4.08 & 5.12 & 5.59 & 379.57 & 1896.03 & 408.45 & 2040.31 \\
\hline $200 \times 38 \times 1.4$ & 0.25 & 6.61 & 7.20 & 8.63 & 550.83 & 2179.63 & 562.78 & 2226.93 \\
\hline $200 \times 51 \times 0.7$ & 0.17 & 1.23 & 1.01 & 0.76 & 73.93 & 425.70 & 80.81 & 465.35 \\
\hline $200 \times 51 \times 0.9$ & 0.22 & 2.04 & 2.67 & 2.48 & 140.29 & 630.86 & 158.12 & 711.02 \\
\hline $200 \times 51 \times 1.1$ & 0.27 & 3.04 & 3.48 & 3.74 & 272.04 & 1004.88 & 279.52 & 1032.52 \\
\hline $200 \times 51 \times 1.4$ & 0.34 & 4.93 & 5.06 & 6.08 & 353.87 & 1033.25 & 374.02 & 1092.10 \\
\hline $200 \times 51 \times 1.9$ & 0.46 & 9.07 & 10.73 & 11.30 & 843.61 & 1833.51 & 863.79 & 1877.37 \\
\hline
\end{tabular}

(where An. refers to the results of theoretical analysis, Ex. refers to those of experiment research, Nu. refers to those of numerical simulation.) 


\subsection{Numerical Simulation for Static Compression of Honeycomb Thin-walled Circular Steel Tubes and Results Comparison}

The numerical simulation of circular steel tubes is made. The model size is the same as the size in the experiment. The model is shown in Figure 15, taking aligned configuration for example.

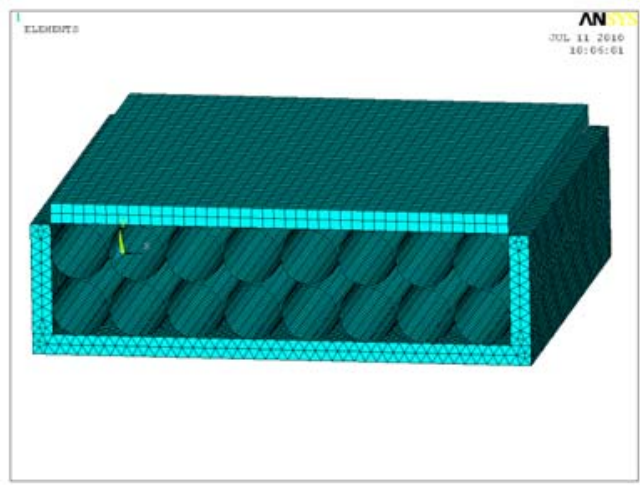

Figure 15. Numerical Analysis Model of Honeycomb Thin-walled Circular Tubes

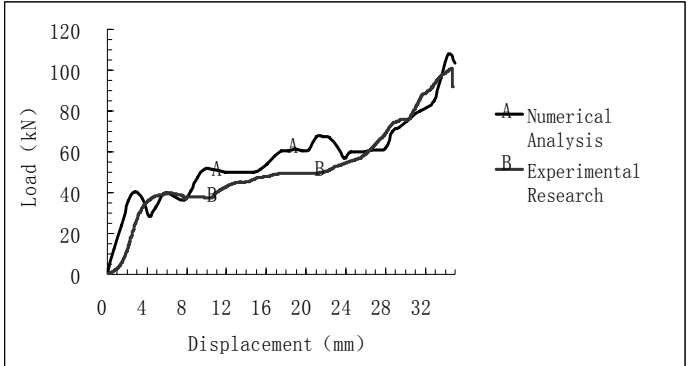

Figure 16. Load-displacement Curve of Honeycomb Thin-walled Circular Tubes

(Aligned Configuration)

The load-displacement curve of honeycomb thin-walled circular tubes with aligned configuration is shown in Figure 16. The results of experiment and numerical simulation agree well. At the beginning, elastic deformation occurs and the load-displacement curve is linear. As the load increases, some tubes begin to yield and the curve is subdued. When the load continues to increase, the curve rises up. However, the result of numerical simulation is slightly larger than that of experiment research. When the circular tubes are flattened, the honeycomb tubes can not absorb energy.

From Table 4 and Table 5, the average bearing capacity of single thin-walled circular steel tubes is lower than the corresponding one that arranged in a honeycomb structure. This difference is caused by the constraint among the honeycomb circular tubes configurations. It will increase the bearing capacity of the thin-walled circular steel tube. In theory the thicker the configuration is, the more the bearing points have, the larger the bearing capacity is. The real bearing capacity of the two configurations, the value of the staggered configuration is larger than that of the aligned configuration. However the absorbed energy of the circular steel tube with aligned configuration is larger than that of the circular steel tube with staggered configuration. 
Table 4. Results Comparison of Honeycomb Thin-walled Circular Steel Tubes

\begin{tabular}{|c|c|c|c|c|c|c|c|c|c|c|}
\hline \multirow[b]{2}{*}{ Configuration } & \multirow[b]{2}{*}{$\begin{array}{c}\text { Number } \\
\text { of } \\
\text { Tubes }\end{array}$} & \multicolumn{5}{|c|}{ Yield Load（kN） } & \multicolumn{4}{|c|}{ Bearing Capacity ( $\mathrm{kN})$} \\
\hline & & $\begin{array}{l}\text { Whole } \\
\text { Tubes } \\
\text { (Ex.) }\end{array}$ & $\begin{array}{l}\text { Whole } \\
\text { Tubes } \\
\text { (Nu.) }\end{array}$ & $\begin{array}{l}\text { Single } \\
\text { Tubes } \\
\text { (An.) }\end{array}$ & $\begin{array}{c}\text { Single } \\
\text { Tube } \\
\text { (Ex.) }\end{array}$ & $\begin{array}{l}\text { Single } \\
\text { Tube } \\
\text { (Nu.) }\end{array}$ & $\begin{array}{l}\text { Whole } \\
\text { Tubes } \\
\text { (Ex.) }\end{array}$ & $\begin{array}{l}\text { Whole } \\
\text { Tubes } \\
\text { (Nu.) }\end{array}$ & $\begin{array}{c}\text { Single } \\
\text { Tube } \\
\text { (Ex.) }\end{array}$ & $\begin{array}{l}\text { Single } \\
\text { Tube } \\
\text { (Nu.) }\end{array}$ \\
\hline Single Tube & 1 & 2.20 & 2.85 & 2.51 & 2.20 & 2.85 & 8.13 & 8.85 & 8.13 & 8.85 \\
\hline $\begin{array}{c}\text { Aligned } \\
\text { Configuration } \\
\text { with Tow } \\
\text { Row }\end{array}$ & 16 & 29.18 & 28.71 & 1.53 & 1.82 & 1.79 & 80.49 & 104.15 & 10.06 & 13.02 \\
\hline $\begin{array}{c}\text { Staggered } \\
\text { Configuration } \\
\text { with Two } \\
\text { Row }\end{array}$ & 15 & 30.14 & 25.80 & 1.57 & 2.01 & 1.72 & 71.93 & 121.20 & 10.28 & 15.15 \\
\hline $\begin{array}{c}\text { Aligned } \\
\text { Configuration } \\
\text { with Three } \\
\text { Row } \\
\end{array}$ & 24 & 44.65 & 45.80 & 1.53 & 1.86 & 1.91 & 100.01 & 130.01 & 12.50 & 16.25 \\
\hline $\begin{array}{c}\text { Staggered } \\
\text { Configuration } \\
\text { with Three } \\
\text { Row }\end{array}$ & 23 & 44.27 & 39.10 & 1.57 & 1.92 & 1.70 & 99.20 & 116.50 & 14.17 & 16.64 \\
\hline
\end{tabular}

Table 5. Results Comparison of the Whole Absorbing Energy for Honeycomb Thin-walled Circular Steel Tubes

\begin{tabular}{|c|c|c|c|c|c|}
\hline & \multirow{2}{*}{ Number } & \multicolumn{4}{|c|}{ Whole Absorbing Energy (J) } \\
\cline { 5 - 7 } of & Tubes & $\begin{array}{c}\text { Whole } \\
\text { Tubes } \\
\text { (Ex.) }\end{array}$ & $\begin{array}{c}\text { Whole } \\
\text { Tubes } \\
\text { (Nu.) }\end{array}$ & $\begin{array}{c}\text { Single } \\
\text { Tube } \\
\text { (Ex.) }\end{array}$ & $\begin{array}{c}\text { Single } \\
\text { Tube } \\
\text { (Nu. })\end{array}$ \\
\hline Single Circular Tube & 1 & 73.84 & 74.90 & 73.84 & 74.90 \\
\hline $\begin{array}{c}\text { Aligned Configuration } \\
\text { with Tow Row }\end{array}$ & 16 & 1595.83 & 1541.00 & 99.70 & 96.31 \\
\hline $\begin{array}{c}\text { Staggered Configuration } \\
\text { with Two Row }\end{array}$ & 15 & 1365.00 & 1290.12 & 91.00 & 86.01 \\
\hline $\begin{array}{c}\text { Aligned Configuration } \\
\text { with Three Row }\end{array}$ & 24 & 2513.30 & 1930.00 & 104.70 & 80.42 \\
\hline $\begin{array}{c}\text { Staggered Configuration } \\
\text { with Three Row }\end{array}$ & 23 & 2405.30 & 1830.00 & 104.60 & 79.57 \\
\hline
\end{tabular}

\section{APPLICATION AND CONCLUSIONS}

The results in this paper may be useful in designing a steel retractable roof structure with respect to passive collision protection. Steel grid structures are applied in retractable roof structure, whose span is over $60 \mathrm{~m}$. Thin-walled circular steel tubes, as the energy absorption device, are welded in the lateral contact area in Figure 17. (Black bold lines stands for thin-walled circular steel tubes) Through the numerical analysis, the collision of the moving roofs are modeled. It shows that thin-walled circular steel tubes reduce the collision response of the moving roofs. When the collision of the moving roofs occurs, the absorbed energy of the tubes increases. And the moving roofs' s initial impact force and bearing reaction decrease. Space lacks for a detailed description of it.

Single thin-walled circular steel tube and honeycomb thin-walled circular steel tubes with 4 configurations under static compression are conducted. Load-displacement curves are recorded and energy absorption is calculated. Then the numerical simulation verifies the experimental results. Based on the analytical results, the following conclusions can be drawn. 


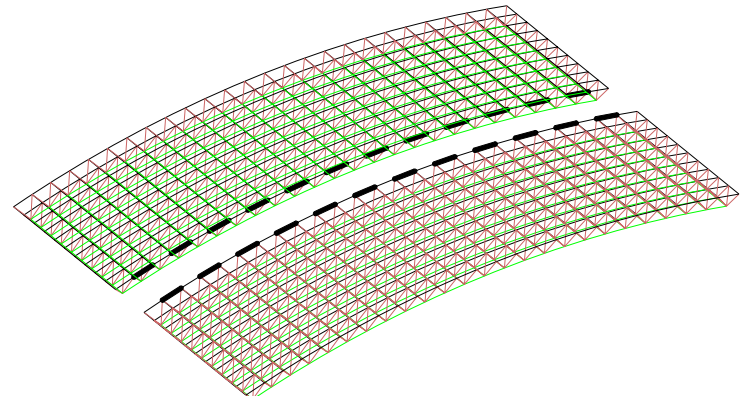

Figure 17. Retractable Roof Structures with Thin-walled Circular Steel Tube

(1) The bearing capacity of single thin-walled circular steel tube is lower than that of one circular tube average value for honeycomb thin-walled circular steel tubes.

(2) The circular steel tube yields by row. Considering the influence of the material nonuniformity and experiment condition, the yield tubes are not in the same row, but the number of the yield tubes is similarly equal to that of the tubes in the same row.

(3) The configuration of staggered thin-walled circular steel tubes with value between 20 and 30 exhibits good bearing capacity. The configuration of aligned thin-walled circular steel tubes of values between 30 and 45 exhibits good energy absorbing characteristic.

(4) With respect to the bearing capacity and energy absorbing characteristic, the numerical simulation verifies the experimental results.

(5) Steel grid structures are applied in retractable roof structure, whose span is over 60m. Thin-walled circular steel tubes can be welded in the lateral contact area. It is a technique of passive safety protection. It achieves the aim to avoid the collision accidents of movable roofs.

\section{Nomenclature}

F $\quad$ static radical load which the circular steel tube bears

$R \quad$ radius of the tube

$M(\alpha) \quad$ moment of hyperstatic curved beam, $0 \leq \alpha \leq \frac{\pi}{2}$

$M_{\max } \quad$ the maximum of section moment

$\sigma_{\max } \quad$ the maximum of bending stress

$L \quad$ length of the tube

$t \quad$ thickness of the tube.

$D \quad$ outer diameter of the tube

$D / t \quad$ ratio of the outer diameter and thickness of the tube

$W \quad$ section modulus

$f \quad$ the yield stress of the circular steel tube

$F_{y} \quad$ the yield load of the tube under compression

the absorbed energy in the whole compression which can be calculated by

EN integral of load-displacement curve, $E N=\int_{0}^{l} F d s$

$s \quad$ the displacement of the circular steel tubes in static radical compression

Es specific energy absorption(SEA), $E_{s}=\frac{E N}{m}$

$m \quad$ the mass of the circular steel tube

$E \quad$ elastic modulus

$\rho$ material density of the circular steel tube 


\section{ACKNOWLEDGEMENTS}

This project is supported by the National Science Foundation of China (No. 51078259) and the Seed Foundation of Tianjin University (No. 03-19). The support is gratefully acknowledged. The technical consultation provided by Professor Han Zhu and Xiliang Liu throughout the whole process is appreciated.

\section{REFERENCES}

[1] Abrhamson, G.R., "Dynamic Plastic Flow Buckling of a Cylindrical Shell from Uniform Radial Impulse Procedures”, Forth US National Congress of Applied Mechanics, 1962, No. 3, pp. 939-950.

[2] Lindberg, H.E., "Dynamic Plastic Buckling of Thin Cylindrical Shell Containing an Elastic Core”, J. Appl. Mech., 1965, No. 1, pp. 803-812.

[3] Gupta, N.K., Easwara, Prasad, G.L. and Gupta, S.K., "Axial Compression of Metallic Spherical Shells between Rigid Plates”, Thin-Walled Structures, 1999, Vol. 34, No.1, pp. 21-41.

[4] Gupta, N.K. and Venkatesh., "Experimental and Numerical Studies of Dynamic Axial Compression of Thin Walled Spherical Shells”, International Journal of Impact Engineering, 2004, Vol. 30, No. 8-9, pp. 1225-1240.

[5] Ru, C.Q. and Wang, R. "Two Problems about Plastic Buckling of the Cylindrical Shell from under Radial Impulse Load” (in Chinese), Chinese Journal of Solid Mechanics, 1988, No. 3, pp. 101-109.

[6] Gu, W.M., Liu, T.G., Tang, W.Y. and et al., "Dynamic Plastic Buckling of A Cylindrical Shell with Finite Length under Radical Impulse Load” (in Chinese), Chinese Journal of Applied Mechanics, 1995, No. 4, pp. 88-95.

[7] Zeng, S.Y., Yan, L.H., Chen, B. and et al., "Modal Solution of Large Plastic Deformation Problem for Multi-row Energy Absorbing Units under Shock Waves” (in Chinese), Chinese Journal of Solid Mechanics, 1999, Vol. 20, No. 3, pp. 237-244.

[8] Gu, H.J., "Structure Response of Multi-row Cylindrical Shells under Explosion and Shock" (in Chinese), Ph.D. Thesis, Nanjing University of Science \& Technology, Nanjing, 2003.

[9] Du, X.W. and Song, H.W., "Impact Dynamics of the Cylindrical Shell and Crashworthiness Design” (in Chinese), Science Press, 2004.

[10] Zhang, F.W and Liu, X.L, "Research on the Development and Retractable Mechanism of Retractable Roof Structure” (in Chinese), Steel Construction, 2001, Vol. 16, No. 54, pp. 1-6.

[11] Guan, F.L, Cheng, Y., Yu, Y.H. and et al., "Structural Design of Retractable Roof Structure” (in Chinese), Journal of Building Structures, 2005, Vol. 26, No. 4, pp. 112-116.

[12] Kazuo, Ishii, “Structural Design of Retractable Roof Structures”, WIT Press, 2000.

[13] Chen, Y.Y, Jiang, X.F. and Cheng, Y.J., "Study on Extreme Cases for Large-Span Retractable Roof Structure” (in Chinese), Journal of Building Structures, 2007, Vol. 28, No. 1, pp. 21-27.

[14] He, T., Yang, J., Jin X., and et al., “A Textbook of Nonlinear Finite Element Analysis (ANSYS 10.0/LS-DYNA)” (in Chinese), China Machine Press, 2007. 